\title{
O PRINCÍPIO DA PRECAUÇÃO COMO CRITÉRIO DA ADMINISTRAÇÃO PÚBLICA PARA REGULAR A INSERÇÃO DE ORGANISMOS GENETICAMENTE MODIFICADOS
}

\author{
THE PRECAUTIONARY PRINCIPLE AS DISCRETION OF PUBLIC \\ ADMINISTRATION TO REGULATE THE INSERTION OF GENETICALLY \\ MODIFIED ORGANISMS
}

\author{
Gabriele Borges Rodrigues* \\ Leonardo da Rocha de Souza**
}

\begin{abstract}
Resumo: O objetivo deste artigo é analisar o princípio da precaução como critério utilizado pela Administração Pública para a liberação de organismos geneticamente modificados (OGMs). Para isso, realiza-se um estudo a respeito da importância do princípio da precaução para a realização da proteção ambiental, trazendo-se um enfoque da sua regulação em instrumentos internacionais. A seguir, trabalha-se com os problemas provenientes da incerteza científica e como eles afetam o dever que o Estado tem de evitar danos, incertezas essas que geram dificuldades para a aplicação do princípio da precaução. Esse contexto leva este texto a algumas propostas de soluções para Administração Pública aplicar o princípio da precaução apesar (e em virtude) das incertezas científicas. Permeia o texto, e enfatiza-se ao final, uma aplicação do princípio da precaução na liberação de organismos geneticamente modificados. A abordagem é realizada utilizando-se o método hipotético-dedutivo, levantando-se hipóteses e possibilidades para aplicação prática do princípio da precaução na atuação da Administração Pública. Utiliza-se a técnica de pesquisa de documentação indireta, com a revisão bibliográfica de obras nacionais e estrangeiras, incluindo periódicos e textos normativos. Como resultado, pretende-se que este artigo subsidie o aperfeiçoamento de políticas públicas de proteção ambiental, de forma a evitar que as incertezas científicas gerem danos ambientais e propondo-se maior cautela na inserção dos OGMs no meio ambiente.
\end{abstract}

Palavras-chave: Cultura Política; Direito administrativo ambiental; Gestão ambiental; Organismos geneticamente modificados; Princípio da precaução.

\footnotetext{
Abstract: The purpose of this article is to analyze the precautionary principle as a criterion used by public authorities for the release of genetically modified organisms (GMOs). For this, we carried out a study about the importance of the precautionary principle for the realization of environmental protection, bringing a focus of its regulation

* Mestre e Bacharel em Direito pela Universidade de Caxias do Sul (UCS). Assessora Parlamentar. Pesquisadora do Grupo de Pesquisa CNPq "Cultura Política, Políticas Públicas e Sociais". (Vacaria, RS, Brasil). E-mail: gabibr789@gmail.com.

**Pós-doutor em Direito na Universidade Federal do Rio Grande do Sul (UFRGS). Doutor e Mestre em Direito (UFRGS). Procurador do Município de Caxias do Sul/RS. Professor de Direito na Universidade Regional de Blumenau (FURB) e na Universidade de Caxias do Sul (UCS). Pesquisador dos Grupos de Pesquisa CNPq 'Direitos Fundamentais, Cidadania e Justiça' e 'Cultura Política, Políticas Públicas e Sociais'. Editor Científico da Revista Juris Plenum Direito Administrativo. (Blumenau, SC, e Caxias do Sul, RS, Brasil). E-mail: leorochasouza@gmail.com.
} 
O princípio da precaução como critério da administração pública para regular a inserção de organismos geneticamente modificados

on international rules. Next, we work with problems arising from scientific uncertainty and how they affect the duty that the state has to prevent damage, such uncertainties that generate difficulties for the application of the precautionary principle. This context leads this text to some proposed solutions for Public Administration apply the precautionary principle despite (and because) of scientific uncertainty. During the text, with an emphasis on end, we carry out an application of the precautionary principle in the release of genetically modified organisms. The approach is performed using the hypotheticaldeductive method, rising hypotheses and possibilities for practical application of the precautionary principle in the operation of Public Administration. We use the indirect documentation search technique, the literature review of national and foreign works, including periodicals and normative texts. As a result, we intend this article to subsidize the improvement of public policies for environmental protection, in order to prevent the scientific uncertainties, generate environmental damage and proposing greater caution in the insertion of GMOs into the environment.

Key words: Environmental administrative law; Environmental management; Genetically modified organisms; Political Culture; Precautionary Principle.

\section{INTRODUÇÃO}

Catástrofes dos anos 70 e 80 demonstraram que a proteção do meio ambiente necessita de uma política de precaução que vai além do conhecimento científico de um determinado momento. Ao mesmo tempo, um aumento da preocupação com a degradação ambiental no seio da comunidade internacional trouxe uma mudança no sentido de uma preocupação ética emergente, em favor de uma proteção ambiental mais rigorosa (SOUZA, 2013, p. 10-11; LEFF, 2000, p. 190-191).

Um instrumento que a Administração Pública poderia utilizar para tentar evitar danos ambientais seria a aplicação do princípio da precaução, que possibilita a adoção de medidas que impeçam determinada atividade quando, em virtude da ausência de certeza científica, há razoável receio de danos irreversíveis ao meio ambiente ou à saúde humana (MARCHANT, 2003, p. 1798).

Assim, determinada atividade humana é considerada arriscada até que se prove segura. Uma das consequências da aplicação do princípio da precaução é a inversão do ônus da prova, obrigando que o proponente da atividade prove sua segurança (MATTHEE; VERMERSCH, 2000). Ou seja, por meio do princípio da precaução, a Administração Pública tenta antecipar e evitar danos graves ou irreversíveis, como a extinção de espécies (que afetaria a preservação da biodiversidade) e a prevenção de uma mudança climática irreversível (VARDAS; XEPAPADEAS, 2010; PORTOGONÇALVES, 2006, p. 202). 
Mas, quando a Administração Pública tenta aplicar o princípio da precaução, recebe algumas teses contrárias. Os opositores argumentam que o princípio da precaução é uma regra aversiva e altamente conservadora, com riscos que podem sufocar o progresso, a mudança e o crescimento. Defendem que, tomando-se medidas de precaução quando não se tem nenhuma boa razão para fazê-lo, pode-se desperdiçar tempo e recursos e privar a humanidade de benefícios importantes. Nesse sentido, o princípio da precaução seria anticiência e não científico (BROMBACHER, 1999). Ou seja, os que combatem o princípio da precaução, especialmente em sua versão mais forte, defendem que ele não deve ser invocado como solução plena e definitiva para a proteção da saúde e do meio ambiente, tendo em vista a necessidade de se avaliarem os custos e benefícios de sua aplicação (PEREIRA, 2013, p. 106).

Em uma carta ao editor do Jornal de Wall Street, o diretor fundador do Escritório da Agência de Proteção Ambiental (EPA) de Biotecnologia, Henry Miller, escreve: “[...] a aplicação do princípio da precaução tem resultado não-científico, políticas discriminatórias que inflam os custos da investigação, inibem o desenvolvimento de novos produtos, os recursos de resíduos e restringem a escolha do consumidor" (MILLER, 2001, p. A23). Hugh Wise, um cientista do Instituto da Água do Escritório da Agência de Proteção Ambiental, ecoa esse sentimento quando descreve o princípio da precaução como “[...] a aplicação de ciência da sucata a riscos fantasmas para fazê-los parecer plausíveis" (WISE, 2001, p. 16).

Quando a Administração Pública tenta aplicar o princípio da precaução para regular a inserção de organismos geneticamente modificados, essas dificuldades tendem a aumentar. E esse é o objetivo deste artigo. O problema a ser respondido, assim, é: de que forma a Administração Pública pode aplicar o princípio da precaução para evitar os riscos provenientes da incerteza científica que envolve os organismos geneticamente modificados?

O método de abordagem a ser empregado será o hipotético-dedutivo, partindo-se do geral da doutrina sobre o princípio da precaução, para o particular da aplicação desse princípio na inserção de organismos geneticamente modificados. Pretende-se, com esse método, levantar hipóteses e possibilidades (que se encontram no âmbito geral) que permitam sua aplicação na prática (que seria o âmbito particular) na atuação da Administração Pública. Utiliza-se a técnica de pesquisa de documentação indireta, com a revisão bibliográfica de obras nacionais e estrangeiras, incluindo periódicos e textos normativos. 
O princípio da precaução como critério da administração pública para regular a inserção de organismos geneticamente modificados

Para abordar o assunto, este texto inicia com o estudo do princípio da precaução aplicado à proteção ambiental, dando ênfase ao seu alcance internacional (item 2). Depois, destaca-se o problema da incerteza científica em conflito com o dever do Estado de evitar danos (item 3). Isso causa algumas dificuldades para Administração Pública aplicar princípio da precaução (item 4), seguindo-se algumas propostas de soluções (item 5), com uma aplicação na liberação de organismos geneticamente modificados (item 6).

\section{PRINCÍPIO DA PRECAUÇÃO E PROTEÇÃO AMBIENTAL NO DIREITO INTERNACIONAL}

O princípio da precaução foi estabelecido pela primeira vez como um conceito do direito ambiental na Alemanha, nos anos de 1970, quando os governos precisaram lidar com uma série de problemas ambientais de grande escala, como a chuva ácida, a poluição do mar do Norte e a mudança climática global (ZHANG; PEI; LIN, 2010). Desde aquela época, a precaução tem sido invocada em numerosos acordos ambientais internacionais, como a Carta Mundial da Natureza, documento adotado pela Assembleia Geral das Nações Unidas, em 1982, que, no seu princípio 11, “b”, previu o controle das atividades cujos efeitos adversos não fossem completamente conhecidos:

\footnotetext{
Princípio 11. As atividades que possam impactar o meio ambiente devem ser controladas, aplicando-se a elas as melhores tecnologias disponíveis, de forma a minimizar significativos riscos ou outros efeitos adversos ao meio ambiente delas decorrentes, especialmente:

(...) $\mathrm{b}$ - as atividades que possam causar um significativo risco ao meio ambiente devem ser precedidas de estudos exaustivos; os interessados devem demonstrar que os seus potenciais benefícios sobrepõem os potenciais danos ao meio ambiente, devendo ser paralisadas as atividades cujos potenciais efeitos adversos não forem completamente conhecidos (ONU, 1982).
}

Esse princípio 11, apesar de ser uma soft law (SOUZA; LEISTER, 2015), informa que, quando uma atividade puder trazer "significativo risco ao meio ambiente", os interessados devem realizar estudos exaustivos anteriores à implementação dessa atividade e demonstrar que a atividade trará mais benefícios que prejuízos ao meio ambiente. Se os efeitos adversos não forem completamente conhecidos, as atividades devem ser paralisadas.

O enfoque da precaução foi logo incorporado à Conferência Internacional sobre Proteção do Mar do Norte, de 1984, que, em seu Preâmbulo, refletiu a 
conscientização de que os Estados não devem esperar por provas de efeitos prejudiciais para entrarem em ação. Tal modelo encontrou continuidade no texto da Segunda Conferência Internacional sobre a Proteção do Mar do Norte, de 1987, considerada a primeira referência internacional explícita ao princípio da precaução. Vale, por tal motivo, transcrever sua redação:

[...] a fim de proteger o Mar do Norte de possíveis efeitos danosos da maioria das substâncias perigosas, uma abordagem de precaução é necessária, a qual pode exigir uma ação para controlar os insumos de tais substâncias mesmo antes que um nexo causal tenha sido estabelecido por evidencia clara e absoluta (PLATIAU; VARELLA, 2004, p. 14).

A ideia de precaução passou, assim, a ser introduzida nos instrumentos internacionais relativos à proteção do meio ambiente. Contudo, foi ao longo dos anos 90 que se deu a consolidação do princípio. No Tratado de Maastricht de 1992, além de ter sido criada a União Europeia, foi adotado o Princípio da Precaução no Direito Ambiental Europeu, definindo que, na dúvida sobre a periculosidade de certa atividade para o ambiente, decide-se a favor do ambiente e contra o potencial poluidor (CUNHA et al., 2013, p. 72). Na Declaração do Rio de 1992, sobre ambiente e desenvolvimento, no seu principio 15 , descreve-se o princípio da precaução, como segue:

Princípio 15. Com a finalidade de proteger o meio ambiente, os Estados deverão aplicar amplamente o critério de precaução conforme suas capacidades. Quando houver perigo de dano grave ou irreversível, a falta de certeza científica absoluta não deverá ser utilizada como razão para que seja adiada a adoção de medidas eficazes em função dos custos para impedir a degradação ambiental (ONU, 1992).

A definição do princípio da precaução na conferência de Wingspread, mais conhecida como a "Declaração de Wingspread" (realizada em janeiro de 1998), foi amplamente utilizada:

\footnotetext{
Uma atividade representa ameaças de danos à saúde humana ou ao meioambiente, medidas de precaução devem ser tomadas, mesmo se as relações de causa e efeito não forem plenamente estabelecidas cientificamente (...). Neste contexto, ao proponente de uma atividade, e não ao público, deve caber o ônus da prova. (..) O processo de aplicação do princípio da precaução deve ser aberto, informado e democrático, com a participação das partes potencialmente afetadas. Deve também promover um exame de todo o espectro de alternativas, inclusive a da não ação (ONU, 1998).
}

No mesmo sentido, a União Europeia consagra o princípio da precaução no processo de decisão ambiental da seguinte forma: "[...] O princípio da precaução aplica- 
O princípio da precaução como critério da administração pública para regular a inserção de organismos geneticamente modificados

se quando os dados científicos são insuficientes, inconclusivos ou incertos e uma avaliação científica preliminar indica que existem motivos razoáveis de preocupação" (CUMMINS, 2000).

O assunto também foi tratado no Protocolo de Cartagena de 2000 sobre Biossegurança, que regulamenta o movimento internacional de organismos geneticamente modificados (OGMs). Ainda assim, o princípio da precaução também está explicitamente referido nas políticas ambientais de vários países (por exemplo, Canadá, Austrália e Suécia). Ademais, o Departamento de Agricultura e a Administração de Medicamentos e Alimentos dos Estados Unidos afirmam que políticas de segurança alimentar estão firmemente fundamentadas em uma abordagem de precaução. O princípio da precaução, portanto, é amplamente reconhecido e adotado como base para tomar decisões em condições incertas (RAFFENSPERGER; BARRETT, 2001, p. 811), que permeiam as decisões que a Administração Pública deve tomar para evitar danos, como estudado a seguir.

\section{A INCERTEZA CIENTÍFICA E O DEVER DA ADMINISTRAÇÃo PÚBLICA DE EVITAR DANOS}

O princípio da precaução não determina a paralisação da atividade, mas, sim, que ela seja realizada com os cuidados necessários, até mesmo para que o conhecimento científico possa avançar e a dúvida possa ser esclarecida. Portanto, a aplicação do princípio da precaução exige que algumas intervenções (ações) sejam realizadas pela Administração Pública de forma proativa (SOUZA, et. all., 2015, p. 364-366) antes que o dano real ocorra para os seres humanos ou para o meio ambiente. No entanto, em geral, é necessário certo grau de análise científica inicial antes de o princípio da precaução ser invocado, e que exista uma "plausível" preocupação científica (UNESCO, 2005). De qualquer forma, se permanecer a dúvida, "[...] a decisão sempre deve ser a favor do meio ambiente e da vida" (HUPFFER; et. all., 2016, p. 195).

Para o grupo ambientalista Greenpeace o princípio da precaução é definido da seguinte forma: “[...] Não emita uma substância se não tiver provas de que ela não irá prejudicar o meio ambiente" (LEGGET, 1992, p. 42). Já Setzer (2007, p. 141) entende que o princípio da precaução é um princípio de ação, motivador de atitudes e de gestão ativa - sobretudo de não desistência. Ele corresponde à busca objetiva de redução dos riscos e das incertezas, sem que o ambiente seja submetido a uma soma de moratórias, 
tampouco a um excesso de inovações.

Embora existam diferenças de redação, quatro elementos estão envolvidos no princípio da precaução: 1) existe uma ameaça de dano; 2) a situação apresenta uma falta de certeza científica ou de provas; 3) as relações de causa e efeito ainda não estão comprovadas; e 4) há uma necessidade ou dever de agir (RAFFENSPERGER; TICKNER, 1999). Ou seja, o propósito primeiro do princípio da precaução é o de evitar os danos antes de sua ocorrência ao colocar em escrutínio atividades/produtos que possam impactar negativamente o meio ambiente ou a saúde humana e animal, independentemente da existência de certeza científica. Da mesma forma, o princípio da precaução procura incitar ações preventivas (ações de mitigação/adaptação às mudanças climáticas), também na ausência de certeza científica sobre as possíveis causas e/ou consequências. É nesse sentido que o princípio da precaução deve ser entendido: não no sentido de apresentar respostas categóricas sobre os riscos; mas, sim, no sentido de provocar discussões (a priori) sobre os possíveis riscos antes mesmo de se concretizarem (MORAES, 2011, p. 93). Da mesma forma, o princípio da precaução não deve ser visto como um freio à ciência, mas sim como "um freio ao imediatismo capitalista", ou seja, a aplicação desse princípio não deve ser vista como uma forma de impedir o progresso e a atividade econômica, mas, sim, como uma forma de "[...] permitir que ela seja desenvolvida com a maior cautela e análise probabilística possível" (TARREGA, 2008, p. 187-188).

\begin{abstract}
Assim ele [o princípio da precaução] deve ser aplicado, quando houver um risco de danos à saúde pública ou ao meio ambiente. Não basta apenas o risco de dano, este deve ser somado a uma incerteza cientifica constatada. A inversão do ônus da prova compõe o princípio como elemento, pois sem ela o princípio fica inviabilizado na prática, porque, em uma sociedade de riscos, o proponente da atividade potencialmente danosa é quem geralmente possui melhores informações acerca desta e a coletividade, ante a ausência de informações, fica impossibilitada de demonstrar a presença do risco de dano e da própria incerteza científica (WEDY, 2015, p. 133).
\end{abstract}

O princípio da precaução é necessário e justificável, porque a capacidade de prever, calcular e controlar os impactos de tecnologias, tais como organismos geneticamente modificados, é limitada. (RAFFENSPERGER; BARRETT, 2001, p. 811). Para isso, é necessário que a realidade seja percebida sob uma "[...] perspectiva global, complexa e interdependente, que permita compreender a multicausalidade dos problemas ambientais e articular os diferentes processos que intervêm no manejo integrado e sustentado dos recursos" (LEFF, 2009, p. 300). 
O princípio da precaução como critério da administração pública para regular a inserção de organismos geneticamente modificados

A incerteza científica deve trazer uma espécie de alerta que possibilite evitar um dano e impulsione a Administração Pública a agir, calculando e controlando os riscos o máximo possível. A dificuldade, porém, é que as causas e as consequências dos riscos, além de não se limitarem a um espaço geográfico, são difíceis de serem calculados com precisão e, normalmente, não podem ser compensados (BECK, 2011, p. 362-364). Essas e outras dificuldades são abordadas no próximo tópico.

\section{DIFICULDADES DA ADMINISTRAÇÃO PÚBLICA NA APLICAÇÃO DO PRINCÍPIO DA PRECAUÇÃO: O EXEMPLO DOS ORGANISMOS GENETICAMENTE MODIFICADOS}

Uma das dificuldades de aplicação do princípio da precaução está na diversidade de definições que recebe, nem sempre coincidentes. A falta de uma definição clara do princípio da precaução deixa uma grande liberdade de interpretação (MATTHEE; VERMERSCH, 2000). Assim, alguns fatores podem levar ao fracasso da aplicação do princípio da precaução, especialmente quando o conceito se torna fraco para encontrar os problemas devido à dinâmica rápida de alteração nos ecossistemas (LEDOUX et al., 2000), que é uma consequência da gestão tardia (FREITAS, 2012).

Além disso, a participação do público e a colaboração das partes interessadas são necessárias para a solução de longo prazo (BAILEY, 2004) e deve ser um programa permanente, o que geraria um alto custo. Ao mesmo tempo, é possível haver alguma perda de biodiversidade quando se prioriza o desenvolvimento, pois o crescimento econômico induz mais exploração dos bens naturais, além do aumento da demanda da bioenergia (KANONGDATE, 2012).

Mesmo que a precaução venha recebendo grande relevância na regulação ambiental em muitos países, ainda é vaga a legislação a respeito da aplicação do princípio da precaução na tomada de decisão relativa à gestão dos riscos ambientais. Por isso, tem sido largamente referida a necessidade de dispor de quadros reguladores para a implementação operacional desse princípio, de modo a permitir que fiquem mais claros os conceitos e os procedimentos adequados à natureza dos riscos ambientais (GONÇALVES, 2013, p. 139).

O princípio da precaução costuma ser abordado levando-se em conta três realidades: (1) a falta de certeza científica; (2) o risco de danos irreversíveis ou graves; e (3) a obrigação dos Estados de tomarem medidas para impedir atividades incertas (1) e 
arriscadas (2). O primeiro e o segundo componentes contêm certa liberdade de interpretação, de forma que a mesma informação científica pode resultar em diferentes medidas de precaução. São esses dois itens que levam à dificuldade de implementação do terceiro, levando a Administração Pública a dúvidas como: Quando a incerteza científica se torna uma certeza? Qual deve ser a dimensão estimada de um dano sério ou irreversível? Em que nível deve a possibilidade de danos sérios ou irreversíveis ser definida como um risco? Essas perguntas precisam ser respondidas pela Administração Pública para que decida quais medidas deve tomar (MATTHEE; VERMERSCH, 2000). Isso tem levado alguns governos a não tomarem medidas que reduzam o risco possível, justamente diante da impossibilidade de uma certeza científica. Diante disso, orientações da União Europeia sugerem que medidas de precaução permaneçam provisórias até que a certeza científica gerada seja suficiente (JACOBS, 2014).

No que diz respeito aos organismos geneticamente modificados (OGMs), o princípio da precaução tem sido implementado em regulamentos como a Lei de Tecnologia Genética de 1993 na Noruega e na Diretiva do Conselho Europeu 2001/18/EC sobre a libertação deliberada no ambiente de OGM. Desse modo, as aplicações de OGMs oferecerem perspectivas para uma melhor saúde humana e animal, melhor alimentação e proteção do ambiente. No entanto, as preocupações contra algumas aplicações geneticamente modificadas têm aumentado desde o final de 1980 em todo o mundo entre os principais grupos de interesse (por exemplo, consumidores, agricultores e ONGs ambientais). Com isso, esses grupos têm se concentrado especialmente sobre o impacto global sobre o ambiente, a saúde e meios de subsistência rurais que envolvem o cultivo, a comercialização e o consumo de plantas de culturas geneticamente modificadas como alimentação humana e animal (EUROBAROMETER, 2006). A base geral para o debate é conflitante. Os proponentes afirmam que o mundo precisa de culturas geneticamente modificadas para combater a pobreza do futuro, o déficit de alimentos, a fome, as mudanças climáticas, e também defendem que os cultivos transgênicos são seguros e que vão aumentar a produção agrícola (BARBER, 2007).

Por outro lado, as organizações não-governamentais defendem que não estão sendo levadas em conta suas preocupações mais amplas com relação às questões de risco e seu ceticismo em relação aos motivos dos produtores de OGMs. O público considera os OGMs no seu contexto social mais amplo, e levanta questões sérias relacionadas com aspectos socioeconômicos e de biodiversidade. As comunidades de investigação dominam debates relativos a questões de risco (DE MELO-MARTIN; MEGHANI, R. Fac. Dir. UFG, v. 41, n.2, p.110-133, maio / ago. 2017 
O princípio da precaução como critério da administração pública para regular a inserção de organismos geneticamente modificados

2008), e os cientistas muitas vezes diferem em seus pontos de vista, em relação à existência de riscos reais de efeitos adversos na saúde e no meio ambiente (ANDOW; ZWAHLEN, 2006).

De qualquer forma,

[...] não se pode veicular organismos geneticamente modificados sem antes a cuidadosa apreciação do poder público sobre o caso. Os riscos calculáveis devem ser combatidos, com base no princípio da precaução, mesmo que isso fira interesses políticos e econômicos de ordem imediata, sempre sob o discurso do entrave científico. A biodiversidade se encontra como um dos entraves para os organismos geneticamente modificados serem introduzidos na natureza. Além dos danos que a ingestão de algumas espécies de alimentos transgênicos pode causar ao organismo humano, como alergia e câncer, algumas alterações genéticas em animais podem trazer também situações desconfortáveis (TARREGA, 2008, p. 190).

A avaliação dos riscos de culturas geneticamente modificadas resulta em políticas de resultados diferentes, pois dependem de provas científicas e da forma como a Administração Pública interpreta as incertezas associadas. Isso causa discordâncias sobre o significado das evidências científicas, principalmente em relação aos benefícios e riscos da atividade proposta e a adequação e necessidade de estruturas de risco e regulação (MYHR, 2010).

Diante dessas dificuldades, como a Administração Pública pode aplicar o princípio da precaução? O próximo item tenta trazer algumas propostas.

\section{ADMINISTRAÇÃo PÚBliCA E APLICAÇÃo do PRINCíPIO DA PRECAUÇÃO: POSSÍVEIS SOLUÇÕES}

Quando se está diante de argumentos contrários ao princípio da precaução, é necessário se eles são plausíveis e razoáveis. Resnik (2003, p. 329) defende que se pode usar critérios epistêmicos, tais como a coerência, a analogia e o poder explicativo, para determinar se uma ameaça é plausível, e que se pode usar considerações práticas, tais como eficácia, proporcionalidade, boa relação custo-eficácia, realismo e consistência, para determinar se uma resposta a uma ameaça é razoável. Se ela é tratada com discrição e cuidado, o princípio da precaução pode ser uma abordagem sensata ao se tomar decisões importantes no meio da incerteza científica. Sem essas restrições claramente definidas sobre a sua utilização, o princípio da precaução pode tornar-se torcido em uma regra altamente politizada, paranoica e irracional (RESNIK, 2003, p. 342). 
Para isso, Setzer (2007, p. 9) propõe que se descubra o que o princípio da precaução tem sido, o que ele não é, e o que ele pode vir a ser. O autor entende que ainda é precária a compreensão no Brasil do que o princípio da precaução é, ou mesmo do que ele não é. Os tribunais confundem precaução e prevenção e o princípio da precaução é usado como sinônimo de uma obrigação geral de preservar o meio ambiente ou como justificativa para abstenções. Por isso, uma incorporação mais eficaz desse princípio requer o conhecimento da sua teoria e prática.

A aplicação do princípio da precaução exige que a atuação da Administração Pública seja pautada na realização de análises de riscos, na adoção de parâmetros aptos a balizar sua prática e na utilização de stantards jurídicos. A controvérsia promovida pelo princípio da precaução estimula uma atitude reflexiva com relação à ciência e fortalece, no direito e fora dele, a tomada de decisões envolvendo a opinião pública e a comunidade científica. Dizendo de outra forma, o princípio da precaução é claro em sua substância, mas extremamente vago quando se trata de aplicações práticas (MACILWAIN, 2000, p. 425).

Essa vagueza impede que se forme uma consciência pública dos riscos, pois dificulta o desenvolvimento da capacidade de antecipar, suportar e enfrentar perigos. Se a Administração Pública consegue desenvolver essas capacidades, passa buscar meios de dominar as ameaças, as inseguranças e as causas dos riscos, provavelmente longe das soluções tradicionais. $\mathrm{O}$ instrumento para isso seria fazer " $[$...] corto o largo plazo nuevas exigencias a las instituciones sociales en relación a la educación, la terapia y la política" (BECK, 1998, p. 85), que poderia gerar uma “cualificación civilizatoria clave”, formando capacidades proativas em relação aos riscos, "una tarea esencial de las instituciones pedagógicas" (BECK, 1998, p. 85).

A dificuldade da Administração Pública é decidir que o princípio da precaução é suficiente para adotar "medidas restritivas que, destinadas à diminuição ou à eliminação de riscos ambientais, contraponham-se a eventual promessa ou garantia extracontratual" (PIRES, 2015) realizadas pela própria Administração Pública na tentativa de garantir estabilidade de seu ambiente regulatório.

Em outras palavras, a Administração Pública se vê no dilema entre restringir atividades (para proteger o meio ambiente) ou permiti-las para garantir o desenvolvimento (normalmente econômico). Esse dilema surge porque se formou uma pré-compreensão de que o princípio da precaução se contrapõe "[...] à garantia de estabilidade fornecida pelo tratamento justo e equitativo, pois autoriza a adoção de R. Fac. Dir. UFG, v. 41, n.2, p.110-133, maio / ago. 2017 
O princípio da precaução como critério da administração pública para regular a inserção de organismos geneticamente modificados

medidas restritivas destinadas à redução de riscos ambientais sem que se exija certeza científica sobre o objeto dessas medidas" (PIRES, 2015, p. 170). Por isso, é necessário que existam "boas razões" para autorizar essas medidas restritivas.

Portanto, a aplicação do princípio da precaução no processo de decisão exige que a incerteza científica seja explicitada (MYHR; TRAAVIK, 1999). Para isso, a Administração Pública, ao definir as medidas de precaução, deve deixar claros os problemas identificados que põem em perigo o desenvolvimento sustentável, até mesmo para possibilitar o surgimento de soluções científicas (MATTHEE; VERMERSCH, 2000).

O princípio da precaução é um princípio geral, não um conjunto de regras, e deve continuar respondendo ao contexto lógico, social e ecológico. No entanto, é possível e importante definir orientações processuais de tal forma que sua implementação não seja arbitrária. Logo, Raffensperger e Barrett defendem seis passos para a aplicação do princípio da precaução:

1. Definir políticas sociais, ambientais e econômicas que delineiam metas claras e de longo prazo. [...]

2. Avaliar alternativas. [...]

3. Definir parâmetros de "dano potencial" para todas as alternativas possíveis, incluindo, a longo prazo, danos cumulativos, sinérgicos e indiretos para ambos os sistemas ecológicos e sociais.

4. Analisar as fontes e a extensão da incerteza, incluindo lacunas nos dados científicos, métodos inadequados para prever impactos, a intratabilidade de sistemas complexos, confluentes, e incertezas criadas através de um financiamento insuficiente para estudos relacionados com o risco.

5. Avaliar provas de diversas fontes, incluindo revisão por pares da investigação científica e o conhecimento baseado na experiência de pessoas diretamente envolvidas nas questões.

6. Adotar medidas de precaução adequadas, que podem variar de uma proibição completa ou eliminação progressiva para uma aprovação condicional com disposições de acompanhamento e feedback (RAFFENSPERGER; BARRETT 2001, p. 812).

Com base no processo das autoras, o princípio da precaução não é anticientífico nem antitecnológico. Logo, exige análise científica robusta com muita atenção para a incerteza e com a probabilidade de ambas as conclusões: falsos positivos e falsos negativos. O princípio da precaução também pode estimular direções alternativas para as políticas de regulação e desenvolvimento de tecnologia. Seu poder não reside em travar todas as novas atividades, mas no aumento da atenção às potenciais consequências das ações propostas, mudando o escopo de perguntas que são realizadas sobre as tecnologias, além de encontrar soluções inovadoras para problemas complexos. 
Em outras palavras, a implementação do princípio da precaução não tem por finalidade imobilizar as atividades humanas. Não se trata da precaução que tudo impede ou que em tudo vê catástrofes ou males. O princípio da precaução visa à durabilidade da sadia qualidade de vida dos seres vivos e a continuidade da natureza existente no planeta. A precaução deve ser visualizada não só em relação às gerações presentes, como também em relação ao direito ao meio ambiente das gerações futuras (PRIER, 1996, p. 144).

Acima de tudo, o princípio da precaução é solidamente fundamentado no processo democrático. Nenhum dos passos mencionados anteriormente (RAFFENSPERGER; BARRETT, 2001, p. 812) pode ser implementado sem a tomada de decisão transparente e inclusiva. A falta de processo democrático tem sido a principal fonte de discórdia em torno das culturas dos alimentos geneticamente modificados, estudados no próximo tópico. Em virtude do princípio da precaução, não só isto é eticamente inaceitável, como é um procedimento empobrecido para a tomada de decisões sobre uma tecnologia que agora afeta (voluntariamente ou não) milhões de pessoas e muitas outras espécies em todo o mundo.

\section{A APLICAÇÃO DO PRINCÍPIO DA PRECAUÇÃO NA LIBERAÇÃO DE ORGANISMOS GENETICAMENTE MODIFICADOS}

Uma dificuldade constante encontrada pela Administração Pública é a aplicação do princípio da precaução na liberação de Organismos Geneticamente Modificados (OGMs). O estudo de Narliane Sousa (2012) é capaz de demonstrar essa dificuldade. Ela estudou o princípio da precaução e o processo de liberação de vegetais melhorados e alterados geneticamente, em específico dos Cultivares e dos Transgênicos, sob a ótica jurídica. A autora analisou dois processos de liberação dos Organismos Geneticamente Modificados, que são o arroz "LL62" da Bayer e o feijão "GM Embrapa 5.1" da Embrapa, sendo o primeiro um pedido de experimento, e o segundo um pedido de comercialização. Devido aos questionamentos jurídicos, o estudo analisou se o processo de liberação utilizado pela Comissão Técnica Nacional de Biossegurança (CTNBio) segue o cumprimento dos requisitos mínimos exigidos pelo Princípio da Precaução, bem como se são suficientes para garantir a segurança alimentar e evitar possíveis degradações irreversíveis ao meio ambiente. Do contexto social e legal, restaram evidenciadas as divergências em relação aos referidos pedidos de liberação e o Princípio da Precaução, que encontra um desafio tecnológico único para conseguir ser R. Fac. Dir. UFG, v. 41, n.2, p.110-133, maio / ago. 2017 
O princípio da precaução como critério da administração pública para regular a inserção de organismos geneticamente modificados

respeitado (SOUSA, 2012, p. 11).

No que diz respeito à regulamentação da comercialização de organismos geneticamente modificados (OGMs), diferentes interpretações do princípio da precaução e diferentes percepções da biotecnologia moderna, como uma nova tecnologia que contém novos riscos, levam opiniões diferentes sobre: (1) a necessidade de implementar medidas cautelares; e (2) a forma e o conteúdo das medidas cautelares. Essas interpretações diferentes são suscetíveis de criar restrições à livre circulação de produtos geneticamente modificados. Logo, em um contexto de OGMs, pode haver opiniões divergentes, entre os cientistas, sobre a relevância de um problema, critérios de evidência significativa de dano e se devem ser tomadas medidas para evitar danos (MYHR; TRAAVIK, 1999).

Nesse sentido, percebe-se que o risco da regulação de organismos geneticamente modificados está sujeito a debates científicos e públicos. A liberação de OGMs no ambiente, bem como a utilização de ingredientes alimentares provenientes de fontes geneticamente modificadas, levantam preocupações sobre os impactos ambientais e problemas na área de saúde. Informações científicas sobre os efeitos ambientais e na saúde são limitadas, tanto por parte da indústria quanto por parte das instituições públicas de pesquisa. Não há estudos de longo prazo acerca dos efeitos ambientais e sanitários sobre a utilização de OGMs (WOLFENBARGER; PHIFER, 2000). A literatura científica contém hipóteses e resultados preliminares que indicam possíveis efeitos adversos. Tais efeitos observados "emprestaram" o aumento da credibilidade a outros possíveis, mas não comprovados, processos e interações (MYHR; TRAAVIK, 2002).

Desse modo, Myhr e Traavik (2002) entendem que, para minimizar riscos ambientais e de saúde, uma pré-avaliação da liberação de OGMs deve ser exigida com base em cada caso. Segundo os autores, o objetivo da prática de caso-a-caso é tratar cada lançamento como único, uma vez que cada OGM representa diferentes características genéticas. Logo, cada candidato ou notificador deve obter uma autorização prévia das autoridades e deve realizar ensaios de campo de acordo com um procedimento passo a passo, tudo antes que o OGM possa ser comercializado.

Além disso, as implicações econômicas da regulamentação nacional da proteção do ambiente e da saúde humana, animal, e sanidade vegetal podem ser enormes. Em relação ao comércio internacional de alimentos geneticamente modificados, a seguinte citação ilustra isso claramente. 
As exportações americanas de soja para a União Europeia caíram de 2,6 bilhões anualmente para 1 bilhão [...] Enquanto isso, os exportadores brasileiros estão fazendo um negócio de venda rápida de soja "GE-livre" para compradores europeus [...] James Echle, que dirige o escritório de Tóquio da Associação Americana de Soja, comentou: "Eu não acho que ninguém vai rotular recipientes geneticamente modificados, é como colocar uma caveira e ossos cruzados em seu produto" (CUMMINS, 2000).

É por isso que a disputa comercial entre a União Europeia e os Estados Unidos sobre alimentos geneticamente modificados está trazendo o princípio da precaução para o topo da agenda política. Nesse exemplo em particular, apesar da crescente atenção dada à relação entre ambiente e comércio (UNEP/IISD, 2000), a interpretação dos vários acordos fundamentais em matéria de comércio internacional ainda é uma fonte de controvérsia amarga (GREENPEACE, 2000). Também no âmbito da União Europeia, o princípio da precaução está gerando discussões entre a Comissão e os membros individuais dos Estados em relação aos testes de campo sobre culturas geneticamente modificadas, bem como entre diferentes ministros dentro do governo nacional em relação ao financiamento da investigação sobre os OGMs (MELDOLESI, 2000, p. 919).

Há uma disputa entre interesses econômicos e pontos de vistas opostos, os quais se confrontam, inclusive, no que se refere à adoção de princípios jurídicos para a tomada pública e governamental de decisões sobre a produção e consumo de alimentos transgênicos. Em geral, os atores favoráveis à liberação imediata dos transgênicos fundamentam sua posição nos princípios da equivalência substantiva e do benefício da dúvida, como no caso dos EUA e das empresas transnacionais detentoras da tecnologia, enquanto que os atores contrários a essa liberação aderem ao princípio da precaução, como no caso dos governos, de algumas empresas alimentares, de organizações civis e da população europeia (PESSANHA, 2002, p. 85).

O simples fato de que há "perigo" associado à adoção em larga escala de OGM na agricultura não implica, por si só, que a investigação e a experimentação neste campo devem ser interrompidas completamente. Atuais tendências demográficas mostram claramente que estamos diante de um perigo grave (social, econômico, ecológico) relacionado com a produção de alimentos no futuro, embora a tradução bemsucedida e segura de métodos de alta tecnologia para uma prática agrícola adequada é amplamente reconhecida como sendo problemática. Esse risco se aplica a todas as formas de desenvolvimento agrícola, mesmo quando não utilizados OGMs. No entanto, decidir se há ou não evidências científicas suficientes para justificarem a ação requer uma perspectiva mais ampla sobre os riscos, uma perspectiva que vai além da ciência 
O princípio da precaução como critério da administração pública para regular a inserção de organismos geneticamente modificados

reducionista. Em particular, a ponderação das provas deve ser explícita, com a inclusão de questões práticas, de tecnologias, de meio ambiente e de cultura (GIAMPIETRO, 2002, p. 469).

Assim sendo, a introdução comercial de organismos geneticamente modificados (OGM) revelou uma ampla gama de pontos de vista entre os cientistas e outras partes interessadas sobre as perspectivas da engenharia genética (GE) e sobre como o OGM deve ser regulamentado. Dentro dessa controvérsia, o princípio da precaução tornou-se uma questão controversa com alto apoio de grupos céticos, mas resistiu em virtude da atuação de defensores dos OGMs. Para a Administração Pública, a questão fundamental dentro desses debates é saber como lidar com a falta de compreensão científica e discordância científica (MYHR, 2010, p. 501).

Uma vez que a ausência de provas científicas é uma condição para a aplicabilidade do princípio da precaução, a justificação ou a necessidade da adoção de medidas cautelares não pode ser comprovada cientificamente. Portanto, não será claro se um país aplica o princípio da precaução como um meio de proteger o ambiente ou como uma restrição disfarçada ao comércio. Como o princípio da precaução destina-se a proteger o meio ambiente além do conhecimento científico atual, a sua aplicação não deve ser justificada ou questionada com base em dados científicos isolados. Tal princípio, no entanto, em certa medida, pode concluir se a medida está em conformidade com outras normas nacionais em matéria de proteção ambiental ou de proteção da saúde humana (MATTHEE; VERMERSCH, 2000, p. 69).

Nesse sentido, a vida está intrinsecamente ligada ao conceito de evolução, o que implica que o "risco" é uma característica estrutural e fundamental da vida. Os atuais debates sobre a aplicação do princípio da precaução para a regulamentação dos OGMs são simplesmente apontados para um dilema profundo e muito mais geral, enfrentado por todos os sistemas de evolução. Qualquer sociedade deve evoluir com o tempo e, como consequência, deve ter chances de decidir como e quando inovar (RAVETZ, 2001). Logo, a ciência tem o desafio de permanecer útil e relevante, mesmo diante de um grau inevitável de incerteza e ignorância. A nova natureza dos problemas enfrentados neste terceiro milênio, devido à extrema velocidade das mudanças técnicas e da globalização, implica que cada vez mais a Administração Pública vai enfrentar situações que envolvem fatos incertos, "disputa de valores, apostas elevadas e decisões urgentes" (FUNTOWICZ; RAVETZ, 1991, p. 140). Isto é, quando a presença de "incerteza/ignorância" e "conflito de valor" é cristalina desde o início, não é possível individualizar um objetivo e, 
cientificamente, determinar o melhor curso de ação. Isso requer que se desloque do conceito de "racionalidade substantiva (implica um fluxo unidirecional de informações) para o de racionalidade processual (requer um diálogo de duas vias)" (SIMON, 1983).

Ademais, a incerteza e a complexidade desafiam a noção tradicional da ciência e seu papel privilegiado na tomada de decisões, o que representa desafio, tanto para a identificação dos processos científicos apropriados, como para os processos adequados de participação. A investigação científica é crucial para alcançar uma maior compreensão das vantagens e dos riscos dos OGMs. No entanto, a tomada de decisões sobre o que é aceitável não pode ser baseada apenas na compreensão científica, mas também deve se inserir num quadro normativo. É necessária uma abordagem de precaução para o uso e desenvolvimento de OGMs, de forma a influenciar a investigação científica que tem de ser levada a cabo (MYHR, 2010, p. 522). Isso permitiria o reconhecimento de incertezas e daria uma abertura para considerações normativas e processos participativos.

\section{CONSIDERAÇÕES FINAIS}

Como visto neste artigo, a aplicação do princípio da precaução deve ser considerada quando fica caracterizada a ausência de absoluta certeza científica da não ocorrência do dano ambiental, da impossibilidade de identificar perigo de dano grave ou irreversível, da intolerabilidade da agressão ambiental, além de ter como consequência a inversão do ônus da prova no processo judicial, isto é, o autor do risco potencial deverá comprovar que sua conduta não produzirá danos ao ambiente. Ele se aplica, em resumo, quando há dúvida ou incerteza se uma atividade proposta acarretará lesão ao meio ambiente (ALVES, 2005).

Isso leva a Administração Pública a assumir um papel de gestora de riscos, formulando e implementando decisões políticas que apontem para essa função. Seu desafio passa a ser ingressar em situações que antes estavam nas mãos da ciência e da tecnologia. Para isso, precisa ampliar o espectro de participantes nas decisões que precisa tomar, o que exige dispor de informações mais qualificadas para fundamentarem a formação de opiniões de quem está deliberando. Se antes bastava a autoridade da ciência para legitimar a decisão, agora é necessária a colaboração entre os atores sociais (LEITE; AYALA, 2004, p. 342). Um novo padrão de democracia deve acompanhar essa evolução, permitindo o aumento progressivo de oportunidades de participação e deliberação nas R. Fac. Dir. UFG, v. 41, n.2, p.110-133, maio / ago. 2017 
O princípio da precaução como critério da administração pública para regular a inserção de organismos geneticamente modificados

tomadas de decisões realizadas pela Administração Pública, não como mera consulta, mas com efetivas possibilidades de influenciarem as escolhas que se realizarão. Mais uma vez a legitimidade afasta-se da autoridade científica ou política e passa-se à negociação e a modelos de cooperação que busquem a prevenção dos riscos tendo como base "a cultura, a tradição, o senso comum e a experiência", por meio de "processos bem informados, que oportunizem participação pública e democrática no momento da seleção das escolhas adequadas" (LEITE; AYALA, 2004, p. 343-344, 346).

A racionalidade científica influenciou a noção de que os riscos só existem se reconhecidos cientificamente. $\mathrm{E}$, se os riscos não existem para o direito, a tecnologia e a sociedade, "no serán impedidos, ni tratados, ni resarcidos". Criou-se um "monopolio del juicio científico", obrigando os atingidos a buscar na ciência argumentos e instrumentos para alcançar suas pretensões, causando um abrandamento do conhecimento científico. Se de um lado isso possibilita vislumbrar um ponto de vista diferente, de outro lado traz mais insegurança, pois coloca em dúvida se aquilo que a ciência reconhece como risco realmente o é. "Si [...] es imposible determinar las relaciones causales de forma definitiva y terminante, si la ciencia sólo es un error disimulado a la espera de nuevos datos, si cualquier cosa puede suceder”, questiona Ulrich Beck, “¿de dónde procede entonces el derecho a 'creer' en unos determinados riesgos y no en otros?" A crise da autoridade científica acaba por "favorecer una ofuscación general de los riesgos", impedindo o reconhecimento do risco e, portanto, a tomada de decisões a respeito (BECK, 1998, p. 80).

É difícil, portanto, haver uma certeza absoluta na área ambiental em virtude das diferentes análises realizadas pela ciência e da constante mudança dos fatos e da avaliação da consequência desses fatos. Isso leva a sociedade à necessidade de acreditar em algumas opiniões científicas em detrimento de outras. Como a ciência tornou-se, então, uma questão de fé, a preocupação com os riscos pode ser mitigada, afinal, pode-se acreditar em algumas consequências ambientais e não em outras, e agir de acordo com essa crença. As múltiplas opiniões científicas pode levar a sociedade, portanto, a desconfiar da existência dos riscos, o que afeta diretamente a tomada de decisões da Administração Pública.

Por isso, aqueles que são atingidos pelos riscos ambientais e outros advindos da indústria precisam manter uma dupla posição em relação à ciência: de crítica e de crença. Para identificar os riscos, inicialmente, "es necesario creer (...) en las relaciones invisibles de causalidad entre condiciones objetivas, temporales y espaciales", mesmo 
que sejam "muy divergentes en la mayoría de casos". Também é necessário crer "más o menos en las proyecciones especulativas, que tienen que estar directamente inmunizadas contra las siempre posibles contraargumentaciones" (BECK, 1998, p. 80).

Ou seja, aceitar os riscos apontados pela ciência exige uma abertura para aceitar que as condições apontadas causam as consequências alertadas. Por mais que se prove, cientificamente, essa relação causal, a crença é necessária por que outros cientistas virão defendendo e tentando provar outro ponto de vista. Por isso, a crença na opinião da ciência exige explicação racional dos argumentos capazes de se manterem em caso de haver contra-argumentos (HABERMAS, 2004, p. 100, 104-105).

Aplicando-se essa realidade aos organismos geneticamente modificados (OGMs), este estudo abordou a necessidade de cautela na sua inserção em razão dos possíveis riscos que eles podem causar, principalmente, para a saúde humana, para o meio ambiente e para as futuras gerações. Nesse acentuado progresso biotecnológico, é importante que se tenha prudência no posicionamento quanto à adoção de certos princípios fundamentais para que, assim, ocorra uma redução de incertezas futuras.

A inserção dos organismos geneticamente modificados no mercado de produtos alimentícios deve ser sempre realizada tendo em consideração os possíveis riscos inerentes. Dessa maneira, o princípio da precaução ganha um destaque especial, pois ele busca a existência de uma ação cautelosa quanto à liberação de alimentos transgênicos no mercado, especialmente diante dos riscos à saúde humana e ao meio ambiente, advindos de sua produção e consumo.

Para isso, seguindo os ensinamentos de Raffensperger e Barrett (2001, p. 812), é necessário que a Administração Pública defina metas claras para suas políticas de desenvolvimento sustentável; avalie as alternativas para a justiça social, a proteção ambiental e o crescimento econômico; defina os riscos "aceitáveis" e as alternativas para que os mesmos não ocorram; encontre métodos para verificar a extensão da incerteza; tenha acesso ao maior número possível de opiniões científicas sobre a atividade proposta; adote medidas adequadas para a precaução, mesmo que isso implique na proibição de uma atividade e na sua eliminação progressiva.

Percebe-se, portanto, que a efetividade do princípio da precaução exige que a Administração Pública avance e muito na ação fiscalizadora e regulatória dos OGMs. Isso permitirá que sejam tomadas decisões mais embasadas, facilitando o controle do risco ao meio ambiente, à saúde humana e para as futuras gerações. Tendo em vista que a precaução é uma questão importante para proteção ambiental e para evitar riscos, propõe- 
O princípio da precaução como critério da administração pública para regular a inserção de organismos geneticamente modificados

se que haja uma gestão sensata sobre a incerteza, bem como a inclusão de aspectos normativos para avaliação de riscos e para sua gestão, o que pode ajudar a garantir inovações de OGMs sustentáveis e socialmente robustos no presente e no futuro.

\section{REFERÊNCIAS}

ALVES, Wagner Antônio. Princípios da Precaução e da Prevenção no Direito Ambiental Brasileiro. São Paulo: Editora Juarez de Oliveira, 2005.

ANDOW, D. A.; ZWAHLEN, C. Assessing environmental risks of transgenic plants. Ecological Letters, v. 9, p. 196-214, 2006.

BAILEY, B. (2004) Environmental commons. Disponível em: $<$ http://environmentalcommons.org/precaution.html >. Acesso em 22/12/2015.

BARBER, S. What are we waiting for? EU, Parliament magazine, Jan 29, 2007.

BECK, Ulrich. La sociedad del riesgo: Hacia una nueva modernidad. Trad. Jorge Navarro, Daniel Jiménez e Maria Rosa Borrás. Barcelona, Espanha: Ediciones Paidós Ibérica/S.A.; Buenos Aires, Argentina: Editorial Paidós, 1998.

Sociedade de Risco: Rumo a uma outra modernidade. 2.ed. Trad. Sebastião Nascimento. São Paulo: 34, 2011.

BROMBACHER, M. The precautionary principle threatens to replace science. Pollution Engineering, p. 32-34, 1999.

CUMMINS, R. GMOs around the world. IFOAM - Ecology and Farming, 2000.

CUNHA, G. F.; PINTO, C. R. C.; MARTINS, S. R.; CASTILHOS JR, A. B. de. Princípio da precaução no Brasil após a Rio-92: impacto ambiental e saúde humana. Ambiente \& Sociedade, São Paulo, v. XVI, n. 3, p. 65-82, 2013.

DE MELO-MARTIN, I.; MEGHANI, Z. Beyond risk. EMBO Reports, v. 9, p. 302-308, 2008.

EUROBAROMETER (2006). Europeans and biotechnology in 2005: Pattern and trends, Eurobarometer 64.3, G. Gaskell et al., Brussels: EC D-G research.

FREITAS, Juarez. Sustentabilidade: direito ao futuro. 2.ed. Belo Horizonte: Fórum, 2012.

FUNTOWICZ S.O.; RAVETZ, J.R. A new scientific methodology for global environmental issues. In: COSTANZA, R. (ed.). Ecological Economics. Columbia Press, New York, pp. 137-152, 1991.

GIAMPIETRO, M. The Precautionary Principle and Ecological Hazards of Genetically 
Modified Organisms. AMBIO: A Journal of the Human Environment, v. 31, n. 6, p. 466-470, 2002.

GONÇALVES, V. B. O princípio da precaução e a gestão dos riscos ambientais: contribuições e limitações dos modelos econômicos. Ambiente \& Sociedade, São Paulo v. XVI, n. 4, p. 121-140, 2013.

GREENPEACE 2000. WTO Must Apply the Precautionary Principle. Disponível em <http://www.scoop.co.nz/stories/WO0003/S00124.htm>. Acesso em 24/08/2016.

HABERMAS, Jürgen. Verdade e Justificação: ensaios filosóficos. Trad. Milton Camargo Mota. Rio de Janeiro: Edições Loyola, 2004.

HUPFFER, Haide Maria; WEYERMÜLLER, André Rafael; ALVES, Darlan Daniel. O material particulado e o direito à qualidade do ar das gerações presentes e futuras. Revista da Faculdade de Direito da UFG, v. 40, n. 1, p. 188-207, jan. 2016. doi:http://dx.doi.org/10.5216/rfd.v40i1.31966.

JACOBS, R. J. The precautionary principle as a provisional instrument in environmental policy: The Montreal Protocol case study. Environmental science \& policy, v. 37, p. 161-171, 2014.

KANONGDATE, K.; SCHMIDT, M.; KRAWCZYNSKI, R.; WIEGLEB, G. Has implementation of the precautionary principle failed to prevent biodiversity loss at the national level? Biodivers Conserv, v. 21, p. 3307-3322, 2012.

LEDOUX, L.; CROOKS, S.; JORDAN, A.; TURNER, R.K. Implementing EU biodiversity policy: UK experiences. Land Use Policy, v. 17, p. 257-268, 2000.

LEFF, Enrique. Ecologia, Capital e Cultura: A Territorialização da Racionalidade Ambiental. Trad. Jorge E. Silva. Revisão Carlos Walter Porto-Gonçalves. Petrópolis: Vozes, 2009.

Ecologia, capital e cultura: racionalidade ambiental, democracia participativa e desenvolvimento sustentável. Trad. Jorge Esteves da Silva. Blumenau: Ed. da FURB, 2000 .

LEGGET, Jeremy (org.). Aquecimento Global - o relatório do Greenpeace, Rio de Janeiro: FGV, 1992.

LEITE, José Rubens Morato; AYALA, Patryck de Araújo. Direito Ambiental na Sociedade de Risco. 2.ed., rev., atual. e ampl. Rio de Janeiro: Forense Universitária, 2004.

MACILWAIN, C. Experts question precautionary approach. Nature, p. 407- 551, 2000.

MARCHANT, G. From general policy to legal rule: aspirations and imitations of the precautionary principle. Environ Health Perspect, v. 111, p. 1799-1803, 2003.

MATTHEE, M.; VERMERSCH, D. Are the precautionary principle and the international 
O princípio da precaução como critério da administração pública para regular a inserção de organismos geneticamente modificados

trade of genetically modified organisms reconcilable? Journal of Agricultural and Environmental Ethics, v. 12, p. 59-70, 2000.

MELDOLESI, A. Green ag minister wreaks havoc on Italy's ag biotech. Nat. Biotechnol, v. 18, p. 919-920, 2000.

MILLER, H. Letter to the editor: The bogus precautionary principle. The Wall Street Journal, March 1, 2001.

MORAES, Gabriela Bueno de Almeida. O princípio da precaução no direito internacional do meio ambiente. 2011. 196f. Dissertação (Mestrado em Direito) Universidade de São Paulo - USP, Faculdade de Direito São Paulo, 2011.

MYHR, A. I.; TRAAVIK, T. The Precautionary Principle Applied to Deliberate Release of Genetically Modified Organisms (GMOs). Microb. Ecol. Hlth. Dis., v. 11, p. 65-74, 1999.

MYHR, A. I.; TRAAVIK, T. The Precautionary Principle: Scientific Uncertainty and Omitted Research in the Context of GMO use and Release. Journal of Agricultural and Environmental Ethics, v, 15, p. 73-86, 2002.

MYHR, A.I. A Precautionary Approach to Genetically Modified Organisms: Challenges and Implications for Policy and Science. Journal of Agricultural and Environmental Ethics, v. 23, p. 501-525, 2010.

ONU. Carta Mundial para a natureza (1982). Disponível em: <http://www.meioambiente.pr.gov.br/arquivos/File/agenda21/Carta_Mundial_para_Nat ureza.pdf $>$. Acesso em 28/11/2017.

ONU. Declaração do Rio sobre meio ambiente e desenvolvimento (1992) Disponível em: < http://www.onu.org.br/rio20/img/2012/01/rio92.pdf>. Acesso em 28/11/2017.

ONU. PRECAUTIONARY PRINCIPLE CONFERENCE, Declaração de Wingspread (1998). Disponível em: <http://www. johnsonfdn.org/ conferences/

Precautionary/finpp.html $>$. Acesso em 28/11/2017.

PEREIRA, C. L. A sociedade de risco e os efeitos da paralisia do princípio da precaução. Revista Direito Ambiental e sociedade, v. 3, n. 1, p. 91-107, 2013.

PESSANHA, L.D.R. Transgênicos, recursos genéticos e segurança alimentar: uma análise da judicialização do conflito sobre a liberação da soja $R R$ no Brasil. Cadernos de Debate, v. IX, p. 69-92, 2002.

PIRES, Bernardo Rohden. Arbitragem de investimentos e princípios do direito ambiental: precaução e poluidor- pagador podem exercer papel na interpretação de padrões de tratamento a investidores? 2015. 185f. Dissertação (Mestrado em Direito) Universidade Federal de Santa Catarina - UFSC, Centro de Ciências Jurídicas - CCJ, Programa de Pós-Graduação em Direito - PPGD, Florianópolis, 2015.

PlatiaU, A. F. B.; VARELlA, M. D. Princípio da precaução. Belo Horizonte: Del 
Rey, 2004.

PORTO-GONÇALVES, Carlos Walter. A globalização da natureza e a natureza da globalização. Rio de Janeiro: Civilização Brasileira, 2006.

PRIER, Michel. Droit de I'Environnement. 3. ed., Paris, Dalloz, 1996, p. 144.

RAFFensberger, Carolyn; TICKNER, J. Protecting Public Health and the Environment: Implementing the Precautionary Principle (Island Press, Washington, DC, 1999).

RAFFENSPERGER, Carolyn; BARRETT, Katherine. In defense of the precautionary principle. Nature Publishing Group, v. 19, p. 811-812, 2001.

RAVETZ, J.R. 2001. Safety in the globalising knowledge economy: an analysis by paradoxes. The Journal of Hazardous Material (special issue on risk and governance).

RESNIK, D. B. Is the precautionary principle unscientific? Stud. Hist. Phil. Biol. \& Biomed. Sci. v. 34, p. 329-344, 2003.

SETZER, Joana. Panorama do princípio da precaução: o direito do ambiente face aos novos riscos e incertezas. 2007. 155f. Dissertação (Mestrado em Ciência Ambiental) Universidade de São Paulo - USP, Programa de Ciência Ambiental - Procam, São Paulo, 2007.

SIMON, H.A. Reason in Human Affairs. Stanford: Stanford University Press, 1983.

SOUSA, Narliane Alves de Souza e. Aplicação do Princípio Jurídico da Precaução no Processo Administrativo de Liberação dos Cultivares e dos Transgênicos "Ll62" e “GM Embrapa 5.1”. 2012. 171f. Dissertação (Mestrado em Direito Agrário) Universidade Federal de Goiás, Faculdade de Direito, Programa de Pós-Graduação em Direito, Goiânia, 2012.

SOUZA, Leonardo da Rocha de. A consideração dos ausentes à deliberação ambiental: uma proposta a partir da ética do discurso de Jürgen Habermas. Rio de Janeiro: Lumen Juris, 2013.

SOUZA, Leonardo da Rocha de; HARTMANN, Débora; SILVEIRA, Thais Alves da. Dano ambiental e a necessidade de uma atuação proativa da Administração Pública. Veredas do Direito, v. 12, p. 343-373, 2015.

SOUZA, Leonardo da Rocha de; LEISTER, Margareth Anne. A influência da soft law na formação do direito ambiental. Revista de Direito Internacional, v. 12, p. 767-783, 2015.

TARREGA, Maria Cristina Vidotte B.; ARAÚJO, Ionnara Vieira de; NAVES JUNIOR, Jales R. O princípio da precaução e sua aplicabilidade. Revista da Faculdade de Direito da UFG, v. 32, n. 2, p. 186/195, out. 2010.

UNEP/IISD 2000. Environment and Trade: a Handbook. (http://www.unep.ch/etu/ or 
O princípio da precaução como critério da administração pública para regular a inserção de organismos geneticamente modificados

htpp://iisd.ca/trade/handbook)

UNESCO, 2005. The Precautionary Principle. UNESCO, Paris, France.

VARDAS, G.; XEPAPADEAS, A. Model Uncertainty, Ambiguity and the Precautionary Principle: Implications for Biodiversity Management. Environ Resource Econ, v. 45, p. 379-404, 2010.

WEDY, Gabriel de Jesus Tedesco. Os Fundamentos do Princípio da Precaução. Juris Plenum Direito Administrativo. Ano II, número 08, out/dez 2015, p. 109-138.

WISE, P. (2001). Quoted in B. Cohen (2001). The safety Nazis. The American Spectator, 34 (6), 16.

WOLFENBARGER, L. L.; PHIFER, P.R. The Ecological Risks and Benefits of Genetically Engineered Plants. Science, v. 290, p. 2088-2093, 2000.

ZHANG, K.; PEI, Y.; LIN, C. An investigation of correlations between different environmental assessments and risk assessment. Procedia Environmental Sciences, v. 2, p. 643-64, 2010.

Artigo recebido 27 de agosto de 2016 e aceito em 25 de novembro de 2017 